\title{
The training of Canadian urology residents: Whither open surgery?
}

\author{
Andrew E. MacNeily, MD, FRCSC, FAAP
}

See related article on page 42

Can Urol Assoc J 2010;4(1):47-8

In this issue of CUAJ, Preston and colleagues present a cohort of 2 years worth of graduating Canadian urology residents who were surveyed about perceptions of their training in minimally invasive surgery (MIS) and endourologic surgery. ${ }^{1}$ Most residents (about two-thirds) felt that their clinical laparoscopic experience was good or extensive. Moreover, most residents believe that laparoscopic renal and adrenal surgery are the gold standard, but they are less certain regarding the future value of laparoscopic/robotic prostatectomy. Percutaneous access for endourological stone surgery and tumour ablation are primarily performed by radiologists and urology residents did not report receiving uniform training in these areas. About two-thirds of residents reported that no MIS research was being conducted at their institution. This statement is a worrisome finding if urologists wish to be considered opinion leaders and not merely the technical arm of this sphere of our specialty.

Beyond the obvious and interesting data presented, this survey highlights some of the dramatic changes in the landscape of urological training which have occurred in less than a decade. For example, for many years the most common open operation performed by Canadian urology residents has been radical retropubic prostatectomy. It is with this surgery that residents learned the challenging tasks of cutting, suturing and knot-tying in a tightly restricted anatomic space with the potential for significant blood loss. If we lose this experience to MIS/robotic procedures, it will be difficult to train residents in pelvic surgery; this is already a reality in most jurisdictions in the United States. This trend is concerning given that there is still ongoing debate in Canada about whether the shift to MIS/robotic prostatic surgery is even justified from a cost and outcomes perspective. ${ }^{2,3}$ Furthermore, we have shifted most open renal surgery to laparoscopic approaches. Involvement in these open cases allows residents to develop their surgical skills not just with a specific procedure, but also with abdominal, retroperitoneal and pelvic surgery in general.

The application of MIS technology has become increasingly common in urological training programs and clinical practice. However, there is no data on its effect on resi- dent surgical case volume. Recent interrogation of our national resident procedural database (T-Res, Resiliance Software Inc., Vancouver, BC) revealed that over the last 6 years there has been a significant increase in resident exposure to MIS and a reciprocal decrease in open exposure to all forms of renal and adrenal surgery, pyeloplasty and prostatectomy. ${ }^{4}$ Overall, $33 \%$ of index cases are now recorded by residents as being taught in a MIS fashion. This raises a question regarding whether certain open surgeries should no longer be considered part of the core objectives of training in urology. These objectives are set and periodically revised by the urology specialty committee members. Briefly, procedural objectives are categorized into an " $\mathrm{A}$ ", " $\mathrm{B}$ ", or " $C$ " list according to levels of complexity. Category " $\mathrm{A}$ " procedures are those defined as "... the fully trained resident must be competent to individually perform, in addition to being able to manage the patient prior to, during and after...". Category "B" procedures "... are those that the resident will know how to do, including indications..... the resident may not have actually done one of these procedures independently during the residency training period." Category " $\mathrm{C}$ " procedures "... are those for which the resident will be able to describe the procedure, the indications, and the perioperative complications that might be encountered." 5 Should open renal and prostatic surgeries be reclassified from the " $A$ " list of procedures to the " $B$ " list?

In July 2009 the Accreditation Council for Graduate Medical Education (ACGME) mandated minimal numerical thresholds for procedures as part of the accreditation process for urology residency programs. ${ }^{6}$ It is not hard to imagine a similar edict from our own Royal College in the near future. The next challenge will then be the determination of how many open procedures trainees should be exposed to in order to be considered competent.

Will general urologists of the next generation be relegated to the triage of patients for interventional radiologists and a subset of urologists who are fellowship-trained in complex open procedures? Should we be reconsidering a switch to 2 or more streams of training so that there are competent open surgeons, laparoscopists and endourologists? There are no simple answers to these complex issues which have arisen due to advances in technology. 
MacNeily

Postgraduate Director, UBC Department of Urologic Sciences, UBC, Vancouver, BC

Competing interests: None declared.

This paper has been peer-reviewed.

\section{References}

1. Preston MA, Blew BDM, Breau RH, et al. Survey of senior resident training in urologic laparoscopy, robotics and endourology surgery in Canada. Can Urol Assoc J 2010;4:42-6.

2. Fradet $Y$. Arguments against investing widely in robotic prostatectomy in Canada: a wrong focus on tool box rather than surgical expertise. Can Urol Assoc J 2009:3:486-7.
3. Estey EP. Robotic prostatectomy: The new standard of care or a marketing success? Can Urol Assoc J 2009;3:488-90.

4. T-Res. Resiliance Software, Inc. Vancouver, BC. www.t-res.net. Accessed December 21, 2009.

5. Royal College of Physicians and Surgeons of Canada. Objectives of training in Urology. http://rcpsc.medical.org/information/?specialty. Accessed December 16, 2009.

6. Accreditation Council for Graduate Medical Education. ACGME Program Requirements for Residency Education in Urology. hittp://www.acgme.org. Accessed December 16, 2009.

Correspondence: Dr. Andrew MacNeily, Department of Urologic Sciences, Faculty of Medicine, UBC, Gordon \& Leslie Diamond Health Care Centre Level 6, 2775 Laurel St., Vancouver, BC V5Z 1M9; fax: 604-875-4637; amacneily@cw.bc.ca 